\title{
Más allá del Báltico: la embajada del Almirante de Aragón (1597) y las problemáticas del frente danubiano
}

\section{Beyond the Baltic: the Admiral of Aragon embassy (1597) and the problems of the Danubian front}

\author{
Miguel Conde Pazos \\ Universidad Alfonso X el Sabio \\ mcondpaz@uax.es \\ https://orcid.org/0000-0001-9989-9607
}

Fecha de recepción: 11-02-2020

Fecha de aceptación: 15-07-2020

\section{RESUMEN}

La embajada a Polonia del Almirante de Aragón de 1597 supuso un punto de inflexión en las relaciones entre la Monarquía Hispana y la corona de Polonia-Lituania. La difícil elección de Segismundo III como rey en 1587 no fue reconocida por Felipe II, quien durante años siguió apoyando a su sobrino, el archiduque Maximiliano, en sus aspiraciones al trono polaco. Sin embargo, a partir de 1596 y por influjo de la diplomacia papal, las dos cortes iniciaron un progresivo acercamiento, que culminó con esta embajada. En este artículo describimos algunos aspectos de la misión, centrando nuestra atención en la compleja situación interna de Polonia-Lituania y en una serie de cuestiones en torno al frente danubiano que, olvidadas por la problemática báltica, no han despertado tanto la atención de los historiadores.

Palabras clave: Diplomacia, Felipe II, Segismundo III

Topónimos: Polonia-Lituania, Hungría, Crimea

Periodo: Edad Moderna.

\section{ABSTRACT}

The Admiral of Aragon's embassy to Poland in 1597 was a turning point in the relationship between the Hispanic Monarchy and the Polish-Lithuanian Commonwealth. The difficult election of Sigismund III as king in 1587 was not recognized by Philip II, who for years continued to support his nephew, Archduke Maximilian in his claims to the Polish throne. However, from 1596 onwards, there was a gradual rapprochement that culminated in this embassy. This article describes some aspects of the mission, focusing attention on the complex internal situation of Poland-Lithuania and on a whole series of issues vis-à-vis the Danube front, which, overshadowed by the Baltic problem, have not received so much attention from historians. 
Key words: Diplomacy, Philip II of Spain, Sigismund III

Place names: Poland-Lithuania, Hungary, Crimean

Period: Early Modern Age.

\section{INTRODUCCIÓN}

El 10 de febrero de 1597 hacía su entrada en Varsovia el Almirante de Aragón. El español había realizado un largo periplo por Europa hasta llegar a aquella corte, a la que acudió como embajador extraordinario con el objetivo de representar a Felipe II en el bautizo de una de las hijas del rey de Polonia. Junto a él, un numeroso séquito compuesto por setenta personas, el cual fue recibido con gran boato en la ciudad de Varsovia (Ochoa Brun, 2000: 250; Przezdziecki 1947: 240; Rodríguez Villa, 1899: 589-593). A pesar de que su estancia en Polonia apenas se dilató un mes, su presencia en aquella corte tuvo un gran impacto en la época. El último representante español en trasladarse a la zona había sido don Guillén de San Clemente, quien en 1587 viajó desde Praga para apoyar la candidatura del archiduque Ernesto en la tercera elección real. Una empresa que se saldó con un rotundo fracaso, tras ser elegido Segismundo III Vasa (1566-1632) como monarca y caer preso de los polacos otro de los archiduques en liza: Maximiliano (Conde, 2016: 95-114; Urjasz-Raczko, 2014: 213-232). Desde entonces, las relaciones entre las cortes de Madrid y Varsovia habían estado virtualmente rotas, dado que Felipe II había seguido apoyando las pretensiones de su sobrino Maximiliano en Polonia, incluso cuando Rodolfo II, su hermano, firmó un acuerdo con Segismundo III y el archiduque fue liberado. Por lo tanto, la visita del Almirante marcó un importante paso en la reconciliación entre el rey de España y el Vasa.

Esto, sumado a los planes de actuación conjunta en el Báltico que entonces surgieron, ha despertado el interés de los historiadores por la embajada ${ }^{1}$. La mayor parte de los autores han incidido en las problemáticas del norte de Europa, y más concretamente en los proyectos bálticos que se empezaron a conformar a raíz de la visita. Segismundo III era un monarca católico, que heredó el trono sueco en 1592. Hablamos pues de un príncipe clave en el norte de Europa, un espacio prioritario para Felipe II, donde trató de combatir a los ingleses y holandeses tanto a nivel militar como comercial (Gómez-Centurión, 1988). Segismundo también era un actor importante para el papado, que pretendía impulsar la Reforma Católica en el noreste del continente (Garnstein, 1992). Ambos elementos se imbricaron entre sí, de manera que la diplomacia papal jugó un papel relevante en la reconciliación y posterior conformación de los planes hispano-polacos en la zona.

Menos interés ha suscitado el otro frente que concernía a Polonia-Lituania, el húngaromoldavo, donde en aquel momento transcurría una de las etapas decisivas de la Larga Guerra de Hungría. Este conflicto había estallado en 1593 y en él estuvo fuertemente implicado el papa Clemente VIII (1592-1605), quien envió dinero y tropas a la zona, al mismo tiempo que trataba de concertar a los príncipes para crear una gran alianza antiotomana. Entre los socios prioritarios que buscó estaba el reino de Polonia-Lituania quien,

1 Además de la ya citada obra del conde Przezdziecki (en su versión original,1934), la embajada fue estudiada por María Bogucka (1974: 175-185), quien utilizó fundamentalmente fuentes polacas, así como una relación de la embajada conservada Archivo General de Simancas. También por Ryszard Skowron en varios de sus trabajos (1997: 127-128; 2008: 50-54). La obra de A. Barwicka también hace mención al papel jugado por el Almirante (2009: 303-307). Por la parte española, además del trabajo de Rodríguez Villa y el extenso anexo a la traducción de Przezdziecki hecho por M. Gómez Campillo, se encuentran los volúmenes de M. Á. Ochoa Brun (2000: 250). 
por su situación geográfica y su potencial, podía jugar un papel clave en el conflicto. Sin embargo, los polacos se resistieron a unirse a la Liga, ya fuera por su tradicional política de buen entendimiento con el sultán, o por la desconfianza que causaba en Polonia la expansión de la influencia de los Austrias por la zona (Barwicka, 2009: 297-307). En 1597, la diplomacia papal realizó un nuevo intento, enviando para ello a Enrico Caetani como legado a la dieta de Varsovia que se celebraba en febrero. Una misión que coincidió en el tiempo con la visita del Almirante al reino.

La mayor parte de los trabajos han obviado o apenas se han interesado por esta circunstancia y la posible implicación del Almirante en los asuntos del frente danubiano. Una indiferencia que a priori estaría bien justificada. Al fin y al cabo, el propio embajador, al dar cuenta de su misión, recordó como tenía orden expresa de Felipe II de no interferir en la negociación (Rodríguez Villa 1899: 518). Un imperativo regio que quedó más tarde reflejado en la obra de Antonio Herrera y Tordesillas:

Que pues en la Corte de Polonia hallaría al legado, que yva al tratado de la Liga, no se mezclasse en esso con autoridad suya, sino que lo dexase correr, procurando lo posible que el Papa se enterasse, que no era conveniente por ser mayores los daños que podían proceder della, que el provexo que a su Santidad le avia representado, y que no le dexaba de acudir a este negocio por falta de voluntad, sino por las dificultades que traya consigo, que eran insuperables. Y aviendo conferido y platicado mucho, se fue mostrando con el diverso tiempo, lo que el Rey Catholico dezia, y que el negocio no era menos dificultoso que provechoso (Herrera y Tordesillas, 1612: 680).

Sin embargo, la revisión de las fuentes y el uso de otros documentos inéditos del Archivo Histórico Nacional, de la Bibliothèque Royale de Belgique y de la Real Academia de la Historia, revelan que sí existió por parte del Almirante un interés temprano por las problemáticas de dicho escenario, ya fuera como informador o como intermediario de otras negociaciones. Cierto es que el embajador cumplió sus órdenes, y se abstuvo de actuar de manera oficial en las conversaciones de Caetani -nosotros no tenemos constancia de ello - . Pero sí jugó un papel activo, como después él mismo diría, "como persona privada". Nuestro objetivo en este trabajo es mostrar las distintas formas de su intervención, así como los motivos que le llevaron a actuar, que tuvieron mucho que ver con el propio carácter del embajador y la naturaleza de su misión en Centroeuropa; pero también con la situación interna que se vivía en Polonia-Lituania y la compleja maraña de intereses que se había creado, que en último término impidió una separación estricta entre los asuntos del mar Báltico y el conflicto húngaro.

\section{EL EMBAJADOR Y LAS RELACIONES HISPANO-POLACAS A FINALES DEL $S$. $X V I$}

Don Francisco López de Mendoza y Mendoza (1547-1623) fue una de las figuras más controvertidas de la corte española durante las últimas décadas del siglo XVI y las primeras del siglo XVII. Tercer hijo del marqués de Mondéjar y hermano del duque del Infantado, don Francisco destacó por sus dotes militares, sus inquietudes científico-religiosas y el patrocinio que hizo de las letras. También por su carácter complejo y sus constantes choques con la corte (Rodríguez Villa, 1899; Bouza, 2008: 95-104). Emparentado en primeras nupcias con María Ruíz de Liori Folch de Cardona, de ella recibió el título de Almirante de Aragón, así como unos ricos estados y un sinfín de pleitos a resolver, que se sumaron a los que ya poseía de su propia familia. De hecho, la vida del Almirante estuvo marcada por los reveses en los tribunales, que indirectamente afectaron a su relación con la corte. El primer enfrentamiento lo protagonizó en 1590, al verse envuelto en el polémico matrimonio entre 
el hijo del duque de Alba y la hija del duque del Infantado. Una unión, según varios testigos, patrocinada por el propio Almirante en contra de los deseos de Felipe II, que mandó arrestar a los implicados. La reconciliación con el monarca no se produjo hasta unos años más tarde, gracias al influjo en la corte de los jesuitas y su proyectado matrimonio con una hermana del conde de Chinchón, que nunca se llegó a efectuar. A finales de 1595, Felipe II nombró a don Francisco Mayordomo Mayor del archiduque Alberto, figura con la que a partir de entonces estaría fuertemente vinculado. Con él viajó a los Países Bajos, haciéndose cargo de una parte de las fuerzas militares. En julio de 1596 recibió la orden de viajar a Alemania para tratar una serie de asuntos en nombre de Alberto ${ }^{2}$. Un viaje al que, por orden de Felipe II, en noviembre se sumó como destino Varsovia, siendo nombrado embajador extraordinario por el rey.

La situación en Polonia-Lituania en aquel momento era particularmente compleja, tanto para las relaciones entre Madrid y el país eslavo, como por el propio estado interno del reino. Diez años antes, en 1587, la nobleza, reunida para elegir a un nuevo monarca, había quedado dividida en dos grandes grupos, entre los partidarios de Segismundo, el candidato sueco, y los del archiduque Maximiliano. Una fractura que llevaba fraguándose desde los últimos años del reinado de Esteban Báthory, a raíz del ascenso de Jan Zamoyski (1542-1605). Este noble, proveniente de los estratos medios de su estamento, había acumulado un gran poder en Polonia, hasta convertirse en la mano derecha del monarca. En 1578 fue nombrado Gran Canciller, una posición que aprovechó para amasar una gran fortuna y configurar una extensa clientela (Tygielski, 1990). Dicho ascenso fue contestado por otros nobles, particularmente por los miembros de la poderosa familia Zborowski, quienes se sintieron desplazados y a partir de 1584 buscaron la protección de la Casa de Austria (Anusik, 2018: 287-326). Su principal apoyo dentro de esta familia fue el archiduque Maximiliano quien, tras la muerte de Esteban en diciembre de 1586, se postuló al trono polaco. Este fue proclamado rey por algunos de sus partidarios en agosto de 1587, lo que llevó al archiduque a tratar de forzar su coronación avanzando con un pequeño ejército hacia Cracovia. El resultado de aquella empresa ya lo hemos apuntado: Maximiliano fue derrotado a las puertas de la urbe, siendo posteriormente capturado por las fuerzas de Jan Zamoyski (Conde, 2016: 95-114; Urjasz-Raczko, 2014: 213-232).

Aquellos hechos marcaron la actitud de Felipe II hacia el reino polaco-lituano durante los años siguientes. Para el Prudente, la derrota y posterior encierro del archiduque fueron toda una afrenta para el prestigio de la Casa de Austria, el cual sufrió otro duro revés meses después con el desastre de la Empresa de Inglaterra. El acuerdo alcanzado por Rodolfo II con Zamoyski para obtener la liberación de Maximiliano —paz de Bytom-Będzin— tampoco fue satisfactorio para Madrid, al considerar que dicha paz atentaba contra el prestigio de la casa. Apenas unas semanas más tarde, don Guillén de San Clemente escribió a su homólogo en Roma: "embio a V. M. las capitulaciones de Polonia en las quales no hallara sola palabra que sea en nuestro favor y todo contra la reputación del Emperador"3. Según dicho acuerdo, Maximiliano debía renunciar al trono polaco y sus hermanos, incluyendo el emperador, no debían reconocerle como rey. Sin embargo, el archiduque, tras ser liberado, se retractó de su renuncia, argumentando que había sido arrancada bajo coacción ${ }^{4}$. Pronto encontró el apoyo de Felipe II, quien no reconoció a Segismundo III, a quien se refirió en sus cartas simplemente como "el sueco".

2 Memoria de las cosas de que ha de tratar el Almirante de Aragón..., en Colección de Documentos Inéditos de la Historia de España (en adelante CODOIN), Vol. 41, pp. 433-440.

3 Archivo Histórico Nacional, Sección Santa Sede, leg. 17, fol. 95. San Clemente al conde de Olivares. s.f.

4 Archivo General de Simancas, sección Estado (en adelante, AGS, Est.), leg. 696, f. 67, Don Guillén de San Clemente a Felipe II, Praga, 4-X-1589; AGS, Est., leg. 696, f. 77, San Clemente a Felipe II, Praga, 19-IX-1589. 
La paz de Bytom-Będzin tampoco unió a los polacos. Segismundo III no había sido el candidato preferido por Jan Zamoyski en un primer momento y este sólo le brindó su apoyo en la elección para prevenir el ascenso de sus enemigos. A pesar de todo, el canciller trató de mantener su posición privilegiada, como había ocurrido durante el gobierno de Esteban. Pero Segismundo III no se mostró dispuesto a ser una marioneta: a diferencia del transilvano, él sí que conocía el sistema y la lengua polaca, y se resistió a ceder un ápice de poder (Tygielski, 2010: 239-257). Pronto estalló un conflicto entre el rey y el canciller, en el que el monarca, cuya autoridad era limitada, buscó el apoyo de algunos de los enemigos de Zamoyski, entre los que estaban varios de los antiguos partidarios de los Austrias en Polonia. También realizó un acercamiento a una de las ramas de esta dinastía, la de Estiria, que destacaba por su compromiso confesional. Un acercamiento que contó con el apoyo de la diplomacia papal. En 1592, Segismundo se casó con Ana, hija del archiduque Carlos de Estiria. De esta forma, el rey polaco inauguró una política exterior pro-austriaca que mantendría durante las décadas siguientes. Pero esto no supuso la reconciliación con Felipe II, a quien de hecho se dejó totalmente de lado de aquel matrimonio ${ }^{5}$. Fue Clemente VIII quien durante este tiempo se erigió como principal aliado y valedor de Segismundo III en la Europa católica. Gracias a él, el polaco salió de su aislamiento diplomático, al igual que había ocurrido con Enrique IV en Francia. Más aún, con el estallido de la guerra de Hungría, en 1593, uno de los cometidos de su diplomacia fue el de tratar de reconciliar a toda la Casa de Austria con el Vasa, con el objetivo de unir a los polacos en la Santa Liga (Barwicka, 2009: 297-307).

Fue precisamente el apoyo y las presiones de Clemente VIII, sumado a los intereses en el Báltico, lo que finalmente llevaron a Felipe II a un acercamiento al Vasa. Tras el fracaso de 1588 en Inglaterra, el monarca español sustituyó su política militar por una estrategia de pactos, que tenía como objetivo último establecer un orden nuevo en occidente (Martínez Millán y Carlos Morales, 1998: 257-260). Esto no le impidió intervenir de manera armada en la última fase de las Guerras de Religión en Francia, teniendo tres frentes abiertos a lo largo de la última década del siglo. El papa, en contra, deseaba pacificar la parte más occidental del continente para que la cristiandad pudiera volcarse en la lucha contra los turcos en Hungría. Sin embargo, los primeros intentos de su diplomacia en Madrid a este respecto se saldaron con rotundos fracasos. En aquel momento, la corte española estaba dominada por una serie de ministros del grupo castellano y el propio rey parecía poco dispuesto a sacrificar sus intereses en causas tan remotas. No fue hasta 1596, y gracias al empeño mostrado por Clemente VIII y las presiones ejercidas por María de Austria, cuando Felipe II finalmente se avino a otorgar mayores ayudas para Rodolfo II y su aliado, Segismundo Báthory, a quien se dio el Toisón de Oro (González Cuerva, 2007: 1447-1480). Del mismo modo, el papa promovió la reconciliación con el rey de Polonia, si bien en este punto su interés también estaba relacionado con el papel del monarca en el norte de Europa.

Como ya se ha indicado, Segismundo III heredó el trono de Suecia en 1592. Surgió así la posibilidad de que se estableciera en el Báltico una gran potencia bajo el liderazgo de un monarca católico, lo que hubiera abierto grandes posibilidades a la Monarquía Hispana, siempre deseosa de combatir a los holandeses e ingleses en un espacio donde fundaban gran parte de su riqueza. Pero también al papado, que veía en Segismundo a un monarca comprometido con la fe, capaz de impulsar la catolización en el norte y el este del continente. No obstante, la posición del rey era sumamente precaria en los dos tronos. En PoloniaLituania estaba enfrentado con el canciller Zamoyski y una parte de los nobles, y encontró mucha resistencia cuando trató de partir a Estocolmo. Mientras, en Suecia estaba su tío

5 AGS, Est., leg. 698, f. 221, Guillén de San Clemente a Felipe II, Praga, 12-XI-1591 
Carlos de Södermanland, quien explotó su fe católica y su simpatía por los jesuitas para desacreditarlo (Pärnanen, 1912; Roberts, 1986: 338-393). El culmen de este conflicto llegó en 1599, cuando Segismundo III fue destronado en Suecia, abriendo una guerra fratricida que se extendió durante décadas (Frost, 2000; Oakley, 1992).

A lo largo de estos años jugó un papel importante el nuncio en Polonia, Germánico Malaspina, quien trató de involucrar a la Monarquía Hispana en el conflicto de Suecia por medio de los planes bálticos (Jarmiński, 2012: 177-183). Fueron estos proyectos, así como las posibilidades que podía brindar la amistad del Vasa en el norte, los que finalmente Ilevaron a Felipe II a enviar a un embajador. Para ello, se aprovechó el ofrecimiento hecho por Segismundo III para que el Rey católico sacara de la pila bautismal a Catalina, su hija recién nacida, recurriendo el monarca al Almirante de Aragón, quien por entonces se encontraba en Alemania por orden de Alberto. Al poco de llegar a Varsovia, don Francisco fue recibido por el rey y varios senadores, estableciéndose una junta para estudiar sus asuntos ${ }^{6}$.

\section{LA GUERRA DE HUNGRÍA Y SUS CONEXIONES INTERNACIONALES}

La mayor parte de lo tratado durante aquellos días tuvo que ver con la situación de Europa y las cuestiones bálticas. Sin embargo, sí se puede observar un interés temprano por parte del Almirante por las problemáticas húngaras y la negociación de la Liga en sus cartas. Lo cierto es que el desarrollo de los acontecimientos para entonces dificultaba una diferenciación estricta entre los distintos conflictos de Europa. Ya desde un primer momento, los enemigos de la Casa de Austria habían procurado concertarse, influyéndose los unos a los otros para lograr sus objetivos (Türkçelik, 2015: 39-68). Particularmente intensa fue la labor del representante inglés en Estambul, Edward Barton, quien entre 1589 y 1591 intervino para evitar el estallido de un conflicto polaco-otomano que hubiera podido desviar cualquier proyecto turco contra el Mediterráneo hispano (Kołodziejczyk, 2000: 125-127). Sus acciones en los años siguientes fueron en un sentido similar, tratando de orientar la política exterior otomana en contra de los intereses de Felipe II, también en Hungría.

Estas conexiones imbricaron igualmente con la vida política interna de PoloniaLituania, y más concretamente con el papel jugado por Jan Zamoyski. El canciller tenía una especial influencia la zona sur del reino, donde contaba con posesiones y una red clientelar particularmente intensa. La propia diplomacia de Clemente VIII consideraba a Zamoyski como un interlocutor clave a la hora de negociar la Liga, casi tan importante como el propio rey. Pero también se trataba de una figura hostil a la Casa de Austria, que tenía sus propios proyectos en la región. El canciller juzgaba prioritario el mantenimiento del principado de Moldavia como un estado tapón entre Polonia-Lituania y el Imperio otomano, y deseaba extender su influencia sobre Valaquia y Transilvania. Pero por encima de todo, quería mantener el equilibrio en el Danubio, entre Praga, Varsovia y Estambul. En 1595 intervino militarmente en Moldavia como respuesta a la deposición de su gobernante por parte de un aliado Segismundo Báthory, príncipe de Transilvania, vinculado a su vez con la corte de Praga. Con ello, también quiso prevenir una represalia otomana-tártara que convirtiera el principado en otra provincia turca más. La intervención polaca en Moldavia tuvo un marcado carácter privado y se saldó con un rotundo éxito, al situar a Jeremi Mohyła, príncipe afín, en el poder. Pero también le valió multitud de críticas al canciller por actuar en contra de Segismundo Bathory (Milewski, 2012: 261-286). Entre ellas las de Clemente VIII, quien, sin embargo, redobló sus esfuerzos para impulsar la Liga en Polonia con el envío de Enrico Caetani como legado. Este no tardó en percatarse de la importancia que tenía

6 Embajada de d. Francisco de Mendoza..., CODOIN, Vol. 41, 444-457. 
Zamoyski en la negociación, por lo que mandó a uno de sus secretarios, Bonifacio Vanozzi, a tratar directamente con él?.

El papel de la diplomacia hispana en aquellos acontecimientos había sido más bien discreto hasta aquel momento. Durante meses, don Guillén de San Clemente había advertido en sus cartas cómo el emperador evitaba darle cualquier tipo de información sobre sus conversaciones con los polacos. Esto no le había impedido saber lo difícil que era llegar a un acuerdo, dadas las exorbitantes exigencias de estos últimos para entrar en la Liga. En Praga también se temían los posibles vínculos de Zamoyski y el cardenal Báthory — del que hablaremos más adelante-con los turcos ${ }^{8}$. Tampoco ayudó en nada el poco empeño mostrado por Rodolfo II en la negociación, quien envió a sus emisarios a Polonia muy tarde. En cualquier caso, las relaciones entre Varsovia y Praga no eran las más idóneas en aquel momento. El acuerdo de Bytom-Będzin no había puesto fin a las disputas y el archiduque Maximiliano, que durante esos años comandó el ejército en Hungría, seguía reivindicando derechos sobre la corona polaca. Además, la diplomacia imperial estuvo durante años tratando de implicar a los cosacos de Zaporozhia en la contienda (Vynar, 1975). Una injerencia sobre la soberanía polaca que sentó muy mal entre los nobles.

Es probable que estos impedimentos fueran las "dificultades" de las que Antonio de Herrera y Tordesillas hacía mención en su crónica y que llevaron a Felipe II a no entrar en la negociación. Además, los polacos tenían entre sus exigencias que la Monarquía Hispana se incorporara a la Liga, una declaración explícita que podía comprometer en exceso al rey. Pese a todo, el Almirante no pudo mantenerse ajeno a la cuestión húngara, la cual estuvo presente en toda su misión. Don Francisco había partido aAlemania inicialmente para realizar una negociación familiar en nombre de Alberto y su viaje incluyó varias entrevistas con sus otros hermanos: el emperador Rodolfo II y los archiduques Matías y Maximiliano ${ }^{9}$. Estos dos últimos habían dirigido sucesivamente las fuerzas austriacas en Hungría, saldándose su intervención con sendos fracasos. El más pequeño de los dos, Maximiliano — titulado "rey" en las cartas por sus pretensiones en Polonia-, había sufrido recientemente la derrota más grave de la contienda, la de la batalla de Keresztes. Reunido con el Almirante en Viena, Maximiliano le transmitió su versión de esta campaña, culpando a las relaciones de sucesos de su reciente desprestigio. Más adelante, y ya de camino a Polonia, el Almirante abogó por el envío de nuevas ayudas para Hungría, a ser posible en forma de soldados y no solo de dinero ${ }^{10}$. Hay que señalar que don Francisco, al ser originalmente enviado de Alberto y no estrictamente de Felipe II, disfrutó de una mayor autonomía respecto a la diplomacia hispana, también en su embajada a Polonia. Como él mismo escribió, la comunicación durante su misión no la hizo con Madrid, solo con el archiduque, por lo que pudo tener más presentes sus intereses y los de sus otros hermanos ${ }^{11}$.

7 Real Academia de la Historia (en adelante RAH), K93, 193 y ss. Instrucciones dadas a Vanozzi, en su primer viaje como legado al gran canciller...s.f.

8 AGS, Est., leg. 703, d. Guillen de San Clemente a Felipe II, Praga, 30-IV-1596.

9 Encontramos multitud de informaciones útiles sobre su viaje en un manuscrito de la Biblioteca Real de Bruselas (en adelante BRB), como el listado de sus escalas, algunos gastos, o los cumpleaños de los miembros de la familia real. BRB, Mss. 3353-61.

10 Copia de carta del Almirante mi señor a S. A., Olomouc, 9-I-1597, CODOIN 41, pp. 428-433.

11 "Porque yo no he escrito á España, y cuando lo haga, no trataré de negocios, remitiéndome en ellos á lo que escribo y escribiré de aquí en adelante a Vuestra Alteza": El Almirante de Aragón a Alberto., Cracovia, 25-I-1597, CODOIN, 41, pp. 441-444. 


\section{FUENTES DE INFORMACIÓN}

Antes de su llegada a Varsovia, el embajador pasó por Cracovia, donde se instaló durante unos días. Allí envió uno de sus primeros reportes a Alberto sobre el estado de la negociación de la Liga, en los que se mostraba poco optimista, al considerar excesivas las demandas polacas. En su opinión, la autoridad de Segismundo III era muy escasa frente a una dieta dominada por un sinfín de opiniones, incluyendo las de los "herejes". A su juicio, los polacos se contentarían con mantener la paz con la Puerta, mejorar los acuerdos con los moscovitas y mantener controlados a los tártaros ${ }^{12}$.

¿De dónde extrajo sus informaciones? ¿Cuáles fueron sus posibles fuentes sobre el mundo polaco-lituano, amén de las noticias suministradas por la diplomacia hispana en Praga? Lo cierto es que el Almirante pudo estar bien asesorado por las gentes con las que se entrevistó, así como por algunas figuras de su séquito. En este sentido, cabe destacar el recibimiento que le dieron en Cracovia dos cardenales: Jerzy Radziwiłł (1556-1600) y Enrico Caetani (1550-1599). El primero era un destacado partidario de la Casa de Austria en Polonia. Perteneciente a una de las familias más poderosas de Lituania, Jerzy se había convertido al catolicismo durante su juventud, escalando posiciones dentro en la iglesia. En 1579 viajó a España en un viaje de peregrinación junto a su hermano Stanisław y fue nombrado cardenal cuatro años más tarde. Durante la mayor parte de su vida se mostró como un partidario de Felipe II, tanto en Roma como en Polonia-Lituania. En 1587 apoyó a Maximiliano en la elección, pero pronto se reconcilió con Segismundo III. De hecho, Jerzy jugó un papel clave en el matrimonio de este rey con Ana de Austria. En 1591 fue nombrado obispo de Cracovia, una de las sedes más ricas del reino. El lituano agasajó al Almirante a su llegada a la antigua corte y le aconsejó que permaneciera allí hasta que se reuniera la dieta en febrero, por lo que su comunicación a lo largo de esas semanas pudo ser fluida. Más tarde envió a un caballero para que escoltara al embajador hasta Varsovia. En cuanto a Enrico Caetani, este era un viejo conocido de la diplomacia hispana. Cardenal y Patriarca de Alejandría desde 1585, en 1589 fue enviado a Francia, donde se convirtió en uno de los más ardientes defensores de la Liga Católica. Una posición que favoreció a los intereses del Rey católico, pero que le terminó enfrentando con el papa. Enrico contaba con estrechos vínculos con el mundo hispano: su hermano, Camillo Caetani, era nuncio en Madrid y en Roma se decía que debía el capelo a Felipe II (Borromeo, 1982: 176-200). El Almirante compartió mesa al menos una vez con el cardenal en Cracovia. Allí tuvo la oportunidad de conocer las pocas expectativas que este tenía de su misión ${ }^{13}$. El 14 febrero, Caetani se entrevistó con el rey, el canciller, los mariscales de Polonia y Lituania y otros senadores. Como las veces anteriores, los polacos exigieron dinero, la renuncia de Maximiliano de sus derechos a la corona, así como otra serie de contrapartidas para unirse a la Liga que eran inasumibles para Rodolfo II. Unas semanas más tarde, San Clemente escribiría:

El Cardenal Gaetano se ha buelto a Roma desengañado de la difficultad que ay en concluyrse la liga que Su Santidad ha desseado y no durara tanto este engaño, si los que propussieron esta liga entendieran las difficultades que la ympossibilitavan como los entendio en dos días el Almirante de Aragon ${ }^{14}$.

Por otra parte, hay que tener en cuenta a algunos miembros del séquito que llevó consigo don Francisco. Entre ellos destaca el jesuita Thomas Sailly (1553-1623), quien

12 Ibídem.

13 Ibídem.

14 AGS, Est., leg. 704, d. Guillen de San Clemente a Felipe II, Praga, 5-V-1597. 
más tarde publicaría una relación de la embajada ${ }^{15}$. Este había formado parte de la misión que acompañó a Antonio Possevino a la Europa oriental durante la década de 1580. En 1586 partió a Bruselas para transmitir un mensaje secreto en nombre de Esteban Báthory para Alejandro Farnesio, quien le mantuvo consigo y lo nombró su confesor. De hecho, fue Sailly quien asistió al gobernador en su lecho de muerte. Encargado de la misión castrense, en 1596 regresó a Polonia como parte de la comitiva (Hortal Muñoz, 2004: 90-91). Su conocimiento fue seguro útil para el Almirante, pues estaba familiarizado con la realidad polaca, aunque dada la naturaleza descriptiva de su relación es difícil de concretar.

Otra información valiosa la encontramos en una breve relación de la embajada que se conserva en la Biblioteca Nacional ${ }^{16}$. Está fue escrita por el jesuita Manuel de Céspedes, persona sin aparentes vínculos con la realidad polaca. En su relato —en realidad una misiva a un compañero- se centra en los aspectos formales de la embajada y no trata asuntos políticos. Sí que aporta algunos detalles inéditos, como la descripción de un suceso que aconteció de camino a Varsovia, en el que un integrante de la embajada asesinó a un mozo polaco, por lo que después fue condenado. Dicha pena fue permitida por el Almirante, quien ganó reputación entre los polacos por su rigor. El jesuita también reservó algunas líneas para exponer a grandes rasgos el reino polaco-lituano: su riqueza, su ejército y su sistema de gobierno. Su pobre impresión de la justicia polaca fue compartida más tarde por el Almirante en su relación, utilizando ambos unos términos bastante parecidos para su descripción (Bogucka, 1974). Céspedes también añadió un post scríptum al texto, en el que enumeró los jesuitas españoles que sabía residían en Polonia. Estos eran los padres García Alabiano, Alonso de Pisa, Diego Ortiz y Miguel Ortiz. De todos ellos, el que más interés nos suscita es el primero de todos. Natural de Tarazona, García Alabiano (1549-1624) entró en la Compañía en 1566, pasando a la Academia de Vilna en 1578. Sus lecciones sobre teología pronto le granjearon un gran prestigio, así como el respeto de los reyes. Pero su principal valedor fue el cardenal Jerzy Radziwiłł, de quien fue confesor. En 1592 se trasladó a Cracovia, tras el nombramiento de este como obispo, por lo que debió estar presente a la llegada del Almirante. Durante este tiempo parece que jugó un papel político activo, tomando parte en los desencuentros entre Radziwiłł y el nuncio Malaspina. Tras la muerte del lituano, regresó a Zaragoza, donde fue rector. En cuanto al resto, Alonso de Pisa (15281598) era ya anciano y estaba en Lituania cuando don Francisco arribó a Varsovia. Natural de Toledo, se dedicó a la medicina y la matemática, antes de centrarse en el estudio de la teología y las lenguas. Diego y Miguel Ortiz (1564-1625; c. 1560-1638), por su parte, formó parte del grupo de jesuitas que se instalaron en Transilvania antes de su expulsión en 1588, por lo que pudieron estar familiarizados con las relaciones polaco-transilvanas (Cieślak, 2015: 79-98). Pero su nexo con el Almirante parece menos probable que el de Alabiano.

\section{EL CISMA DE LA FAMILIA BÁTHORY}

La preeminencia de los jesuitas en lo que se refiere a las fuentes de información parece evidente, lo que en el caso del Almirante debió verse reforzado dadas las buenas relaciones que mantenía con la Compañía. Más aún, era esta la que, en gran medida, moldeaba la imagen que se tenía en España de lo que ocurría en aquella parte de Europa. Un caso bien estudiado es el del príncipe Segismundo Báthory de Transilvania (1572-1613), quien se erigió gracias a las relaciones de sucesos y alguna obra teatral en el arquetipo del perfecto príncipe cristiano (González Cuerva, 2006: 277-299; Sambrian, 2013: 541-

15 Brevis narratio legationis Excel.mi D. Francisci de Mendoza..., Bruselas, apud Rutgerum Velpium, 1598. 16 Biblioteca Nacional de Madrid (en adelante, BNM), Mss, 9372, fols. 57-62, De la jornada del Almirante de Aragón, Praga, 30-III-1597. 
554; Sanz Ayán, 2012: 213-248). Una imagen confeccionada en parte por la Compañía, que distaba mucho de la realidad. Por supuesto, había un interés detrás: el regreso de los jesuitas a Transilvania, tras su expulsión en 1588 por presión de los estados, se debió a la protección de los Báthory, por lo que trataron de reforzar su posición en el territorio. En Polonia-Lituania, en cambio, existía una imagen muy diferente del príncipe, como don Francisco pudo comprobar.

El ascenso al trono polaco de Esteban Báthory en 1575 inauguró un periodo de intensificación de las relaciones polaco-transilvanas. Durante esos años, los éxitos militares en Moscovia granjearon al rey un gran prestigio internacional. Especial atención fue la mostrada por el papado, que vio en Báthory a un príncipe capaz de expandir la influencia de la iglesia en la zona, siendo un protector de los católicos y amigo de los jesuitas. Una imagen que el propio monarca tendió a reforzar, al embarcarse en una serie de conversaciones para crear una alianza anti-otomana. Esteban también trató de consolidar la posición de su familia dentro de Polonia-Lituania. Nunca tuvo hijos, pero sí sobrinos, que le acompañaron al reino para servir a sus planes políticos. Entre ellos cabe destacar a los hijos de su hermano mayor: Baltasar Báthory (1555-1594) y Andrés Báthory (1563-1599). El primero optó a la corona polaca, sin éxito; el segundo desarrolló su carrera en la iglesia, siendo nombrado coadjutor del obispado de Warmia y cardenal en 1584. Por otra parte, estaba Griselda Báthory (1569-1590), hija de otro de sus hermanos, quien en 1583 se casó con Jan Zamoyski. Todos ellos parecían tener un destino brillante en Polonia-Lituania: Ios dos hermanos debían perpetuar el poder político y eclesiástico de la familia y Griselda reforzar los lazos de parentesco con el poderoso canciller. Pero Esteban murió demasiado pronto como para asentar sus planes. La candidatura transilvana tuvo poco eco en la elección polaca de 1587 y la esposa de Zamoyski murió dos años más tarde. Durante los meses siguientes, los hermanos parecieron centrar su atención en Transilvania, donde Baltasar heredó el dominio de Fogaras. Allí gobernaba otro de sus primos, el ya mencionado Segismundo Báthory, un joven inestable, que tenía como uno de sus principales consejeros al jesuita español Alonso de Carrillo. Este instó al príncipe a que respondiera a los llamamientos de la diplomacia papal y abandonara el vasallaje turco. Una decisión, adoptada a lo largo de 15594, a la que se opusieron muchos nobles transilvanos, entre ellos Baltasar Báthory. En mayo, ante los desórdenes que surgieron, pareció que este último se haría con el poder. Pero a lo largo del verano la situación se tornó totalmente en su contra, siendo arrestado y ejecutado por orden de Segismundo (Klaniszay, 1983: 31-58; Lukács, 1987: 4º-7º).

La muerte de Baltasar inauguró un cisma entre las diversas ramas de la familia Báthory. Su hermano, el cardenal Andrés, se instaló en Polonia, donde encontró el apoyo de muchos nobles, incluyendo el de Jan Zamoyski, quien como vimos tenía sus propios proyectos en la región ${ }^{17}$. También escribió a Roma, pidiendo que se hiciera justicia por su hermano. Clemente VIII inició una investigación, pero su mayor anhelo era consolidar el apoyo de Transilvania en la guerra, por lo que sobre todo buscó la reconciliación entre los primos. No fue fácil: el 28 de enero de 1595, Segismundo Báthory llegó a un acuerdo con Rodolfo II por el que prácticamente excluía al resto de las ramas de la familia de cualquier pretensión en Transilvania. El acuerdo situó a Segismundo bajo la órbita austriaca, tomando a una archiduquesa como esposa. A partir de entonces, el enfrentamiento dentro de la familia Báthory se convirtió en un elemento sumamente desestabilizador en las relaciones de la región. La red de contactos de Andrés incluyó, además de algunos polacos, a los turcos y los duques de Prusia, gracias a su posición como obispo de Warmia, que le brindó una gran proyección en el Báltico. Más aún, a través de estos últimos, el cardenal también pudo

17 AGS, Est., leg. 702, San Clemente a Felipe II, Praga, 4-IX-1595. 
contar con vínculos en Inglaterra. Una vez más observamos una interrelación estrecha de los distintos frentes en guerra. Andrés también estuvo inmerso en las pugnas internas de Polonia-Lituania. Su relación con Segismundo III no siempre fue buena, pero su mayor rival fue el también cardenal Jerzy Radziwiłł, líder entre los partidarios de los Austria en el reino. Ambos se disputaron el obispado de Cracovia y, tras la elección de Radziwiłł en 1591, el transilvano denunció su nombramiento (Kruppa, 2014: 89-117).

La Biblioteca Real de Bruselas conserva algunos documentos referentes a la embajada. Entre ellos, cabe destacar una relación del Almirante en la que trata esta problemática transilvana desde una perspectiva polaca ${ }^{18}$. En ella habla de un Andrés deseoso de vengar la muerte de su hermano, para lo cual no había dudado en buscar apoyos en Polonia y Estambul. Aquello había llegado a oídos del papa, quien le había dado orden de que se contuviera, siendo sus intrigas toda una amenaza para la estabilidad de la zona. En todo caso, el manuscrito no es un alegato contra el cardenal. Todo lo contrario, en él se describe a Segismundo Báthory como un potentado errático, falto de todo sentido político y bien dispuesto a retirarse:

Y que no hallándose bien el dicho príncipe de Transilvania en aquella provincia o por su condición que dizen no es apta para atender a cosas de mucho gobierno e importancia o por el appetito de peregrinar por el mundo de que dizen es algo tentado ${ }^{19}$.

Esta imagen contrastaba con la percepción general que se tenía del príncipe en España, que cambiaría progresivamente durante los meses siguientes a raíz del empeoramiento de relaciones entre el transilvano y la corte del emperador. Detrás de este juicio crítico del Almirante pudo influir también la compleja relación entre los distintos miembros de la Compañía de Jesús en Transilvania, pues durante el periodo previo a su expulsión habían sido comunes las desavenencias entre los miembros de origen polaco y los húngaros (Crăciun, 2011: 75-93). Por otra parte, el interés del Almirante para obtener información sobre Segismundo pudo deberse a una cuestión práctica: su viaje a la zona coincidió con una de las visitas del transilvano a Praga, por lo que pudo querer informarse sobre él. La reconciliación entre los Báthory llegaría dos años más tarde de la mano del nuncio Germánico Malaspina. Este intervino en un acuerdo cuyo contenido profundo se desconoce, que permitió a Andrés gobernar en Transilvania de manera efímera, sacando al territorio de la órbita austriaca (Kruppa, 2004: 225-229).

\section{LA EMBAJADA TÁRTARA}

La batalla de Keresztes no sólo supuso el hundimiento de la posición de Segismundo Báthory y el desprestigio de Maximiliano. También produjo otros cambios. En Praga llevó a una profunda reorganización de los mandos de guerra. Para ello, el emperador escribió a su hermano Alberto pidiendo capitanes con experiencia. Este respondió con una misiva que incluía varios nombres, la cual circuló por Praga en febrero de 1597 (Bagi, 2019: 35-67). Según Cabrera de Córdoba, fue Francisco de Mendoza quien, consultado por Rodolfo II sobre la lista, recomendó a Jorge Basta como general (Cabrera de Córdoba, 1877: 276). Una información que, a la luz de la coincidencia de fechas, resulta verosímil. Otro cambio tuvo que ver con los tártaros de Crimea. Como ha señalado Evrim Türkçelik (2012: 207-219), la

18 BRB, Mss. 3353-61, fol.88, Artículo de una Relación que haze el Almirante de Aragón de las cosas de los Reyes... Creemos, por la similitud del título, que se trata del mismo documento que se encuentra en la British Library de Londres (Mss. 14010).

19 Ibídem 
muerte de Murad III en enero de 1595 inició una mudanza en el palacio otomano. El nuevo sultán, Mehmed III, quiso distanciarse del gobierno de su padre, sustituyendo a muchas de las figuras que habían ostentado hasta entonces el poder. Surgió así una pugna entre la corte -en la que destacaba la sultana madre Safiye-, los soldados y los antiguos visires. En 1596, el sultán decidió marchar personalmente a la guerra en Hungría. Una campaña que se saldó en octubre con la victoria de Keresztes. Poco después de esta y parece que, como parte de la euforia del triunfo, fue nombrado gran visir Cigalazade Yusuf Sinan Pasha, conocido en España como Cigala. Tradicionalmente, se ha considerado a este visir como el responsable de una serie de cambios, entre ellos la sustitución del Kan de Crimea, Ğazi II Giray (1554-1607). Este último debió su ascenso al trono al favor dispensado por Murad III, por lo que pudo estar entre las figuras prescindibles para su hijo ${ }^{20}$. Es posible que también influyera algún tipo de animosidad personal con Cigala, surgida durante las guerras con Persia. Pero el motivo esgrimido entonces fue que, durante la última campaña, el Khan se había negado a acudir en persona. A finales de 1596 fue sustituido por Fetih I Giray (15581597), considerado más voluble. Los sucesos ocurridos a continuación son confusos. Ğazı II inició una serie de consultas en busca de apoyos, tanto dentro como fuera del Imperio otomano. Por otra parte, la permanencia de Cigala en el poder resultó ser efímera, pues la sultana madre apenas tardó unas semanas en sustituirlo por una figura afín. Este hecho precedió a la reposición de Ğazı I en el kanato, ya que además Fetih I Giray tampoco logró consolidar su autoridad en Crimea (Kortepeter, 1972: 146-153; Türk, 2000: 47-56). Durante este tiempo — febrero de 1597—, llegó una embajada tártara a Varsovia, que contactó con el Almirante.

Las fuentes sobre este encuentro son escasas. Según un documento posterior de la Real Academia de la Historia, don Francisco tuvo una entrevista con dos representantes tártaros quienes, a cambio de 20.000 escudos y 5.000 arcabuces, ofrecieron el apoyo de la horda y cinco plazas en Hungría ${ }^{21}$. Una información corroborada por Antonio de Herrera en su obra. Por otra parte, el literato Antonio Valera hizo mención, a mediados del siglo XIX, de un manuscrito en la Biblioteca Imperial de San Petersburgo llamado Relación del Almirante de Aragón sobre su embajada a Polonia en 1596. De él destacó algunos aspectos de la embajada: el envío de noticias sobre Moscovia y Transilvania, sus contactos con los "cosacos del Boristenes". También la entrevista que el Almirante mantuvo con los tártaros, quienes, tras buscar ayuda entre los polacos -y ante el poco dinero que obtuvieron y su discreto apoyo-, acudieron en secreto al Almirante. Según Valera, este les prometió un subsidio del rey de España en caso de mover la guerra contra el Sultán. Una práctica, en opinión del literato, que fue descubierta por los polacos, a quienes perteneció la relación (Valera, 2000: carta del 10-VI-1857). Ninguno de estos documentos menciona a que Khan respondía dicha embajada, aunque hay un detalle en la relación de Herrera que parece apuntar a Ğazı II Giray:

Esto fue de tanta importancia, que ni en el presente año, ni en el futuro, el turco no se pudo servir de Tártaros, sino de Circasos, gente de poco provecho, y que por estar muy a trasmano de Hungría, llega muy tarde y con mucha costa (Herrera y Tordesillas, 1612: 684).

Esa mención a los circasianos podría responder a los apoyos que tenía Fetih I Giray dentro de este grupo, con cuyos líderes mantenía lazos familiares. En general, estos

20 Sobre la sorpresa que supuso su ascenso: AGS, Est., leg. 694, Avisos de Constantinopla, 1588.

21 RAH, 9-822, fol. 140, Servicios del Almirante de Aragón hechos a los reyes d. Felipe II y d. Felipe II desde el año 1566. 
documentos se muestran favorables a la intervención del Almirante, quien, como persona privada, dijo llevar la negociación a Praga:

Y dejaron de servir con los 100.000 caballos al turco en los años de 1597, 1598, y 1599 que su majestad cesárea se tuvo por muy servido 22.

En efecto, durante los primeros meses de 1597 se abrió un proceso de restitución de Ğazı II Giray sumamente complejo, en el que Fetih I Giray terminó huyendo a Kaffa, Taman y Circasia. Desde allí clamó contra su caída, entorpeciendo la campaña tártara de ese año, antes de ser derrotado y muerto.

\section{CONCLUSIÓN}

El Almirante partió de Varsovia el 1 de marzo de 1597, tras haber mantenido una serie de reuniones con los reyes y otras personalidades de la corte. También de disfrutar de varios banquetes en su honor. Como presente, Segismundo III le dio unas pieles cibelinas, cuatro piezas de plata y joyas para los caballeros de su séquito. El canciller Zamoyski, por su parte, le regaló cuatro caballos polacos. Tardó 6 días en dejar Polonia, pasando a continuación a Praga, donde se entrevistó con el emperador. En general, existe cierta controversia sobre los resultados de su misión. Algunos autores han hecho énfasis en la falta de acuerdos concretos. Otros apuntan al cambio de orientación dado por el rey de Polonia como consecuencia de la embajada. Pocos meses después se produjo la visita de Paweł Działyński a Inglaterra y Holanda en la que, para escándalo de los asistentes, el polaco hizo una declaración favorable a Felipe II en nombre de su rey. Ese mismo año se produjo un envío de grano de Polonia a España muy superior a lo normal (Bogucka, 1974; Skowron, 2008: 53-55). De hecho, ya en su día don Guillén de San Clemente alabó la labor del Almirante:

yo solo dire que ha sido de tanto provecho la venida del Almirante en Alemania y su yda a Polonia que entrambos cabos con su prudencia y buen proceder en los negocios ha honrado la nación Española y a los ministros de Vuestra Majestad y queda con tanto crédito en Polonia quanto ningún estrangero que aya ydo en aquel Reyno en todo lo qual quedo admirado alabando la justicia de España, porque consintió y aun instó, que conforme a las leyes del reyno se juzgasse y executase la sentencia que se dio a un sobreestante de su caballeriza, porque mató a un moço de caballos de un arcabuzazo, cosa de mucho ejemplo en aquel Reyno, en el qual suele ser a vezes más rigurosa la pena que se da por matar a un perro que por matar a un hombre ${ }^{23}$.

Con la embajada, se encaminó la reconciliación entre Segismundo III y Felipe II, y este último reconoció el acuerdo de Bytom-Będzin poco antes de morir. Dos años más tarde su hijo, Felipe III, concedió el Toisón de oro al monarca. Se iniciaba así una dinámica de alineamiento en Europa entre las dos familias, la Austria y Vasa, que se mantendría al menos hasta 1645. Menos suerte hubo en el frente danubiano: a pesar del mayor compromiso mostrado por Madrid, la guerra corrió en general en contra de la Casa de Austria. A partir del año siguiente, la situación en Transilvania, Valaquia y Moldavia —donde los polacos volvieron a intervenir en 1600- entró en ebullición, perdiendo Praga gran parte de su influencia de antaño.

22 RAH, 9-822, fol. 140, Servicios del Almirante de Aragón hechos a los reyes d. Felipe II y d. Felipe II desde el año 1566

23 AGS, Est., leg.707, Don Guillén de San Clemente a Felipe II, Praga, 5-V-1597. 
La misión del Almirante puso en evidencia la creciente interconexión de los diferentes conflictos que asolaban Europa, así como el incremento de los contactos y las redes de información, gracias a elementos como las crónicas y misivas de los padres jesuitas. Una dinámica que no haría más que intensificarse durante las siguientes décadas. También el papel del aristócrata como "bróker" quien, aprovechando la autonomía que le brindaba su carácter de representante de Alberto y su propia autoridad personal, supo conjugar intereses diversos, jugando el papel de intermediario incluso en negociaciones consideradas remotas, como es el caso de su conversación con los embajadores tártaros. Probablemente, el recuerdo la embajada se vio apocado por la convulsa carrera posterior del Almirante. Tras su regreso a Flandes, don Francisco fue hecho prisionero en la batalla de Nieuwpoort (1600). A ello siguió un largo encierro, al que tuvo que sumar el oprobió tras su liberación, al ser considerado por muchos como el responsable de la derrota. Por otra parte, sus estrechos lazos con el archiduque Alberto le terminaron perjudicando en Madrid. Según Rodríguez Villa (1899: 533-541), en la corte se le consideró uno de los máximos responsables de que los archiduques se negaran a revertir la cesión de los Países Bajos a la Monarquía. Lo cierto es que, tras su regreso a Madrid, el Almirante se enfrentó con el régimen de Lerma, en un contexto en el que se fueron sucediendo los reveses en los tribunales. En 1606 sufrió un breve destierro por un incidente menor. Mucho más grave fue la acusación de 1609 por un papel que llegó a manos del rey, que llevó a un largo proceso y su encierro durante cinco años. Durante este tiempo, sus papeles fueron incautados y una parte de su obra pasó al olvido. En 1617 decidió ordenarse sacerdote y en 1622 fue nombrado obispo de la sede de Sigüenza. Murió un año más tarde.

\section{BIBLIOGRAFÍA}

Anusik, Z. (2018), "A few remarks on the history of the Zborowski family in the 16th century with reference to the book by Ewa Dubas-Urwanowicz", Review of Historical Sciences, Vol. XVII, no 3, pp. 287-326.

Bagi, Z. P. (2019), "Giorgio Basta: a Short Summary of a Career", Episodes in AlbanianHungarian Historical Contacts, Budapest, Hungarian Academy of Sciences, pp. 35-67.

Barwicka-Makula, A. (2009), "Rzeczpospolita w planach dyplomacji papieskiej i habsburskiej w okresie wojny austriacko-tureckiej 1593-1606", Polska wobec wielkich konfliktów w Europie nowożytnej. Z dziejów dyplomacji i stosunków międzynarodowych w XV-XVIII wieku, Cracovia, Societas Vistulana, pp. 297-307.

Bogucka, M. (1974), "Misja Franciszka Mendozy i jego opinie o Polsce. Z dziejów stosunków polsko-hiszpanskisch w koncu XVI w", Odrodzienie i Reformacja w Polsce, 19, pp. 175-185.

Borromeo, A. (1982), "España y el problema de la elección papal de 1592", Cuadernos de Investigación Histórica, 2, pp. 176-200.

Bouza Álvarez, F. J. (2008), Papeles y opinión: políticas de publicación en el Siglo de Oro, Madrid, CSIC.

Cabrera de Córdoba, L. (1877), Historia de Felipe II, rey de España, Madrid, Imprenta de Aribau, Vol. IV.

Cieślak, S. (2015), "I gesuiti Spagnoli nella Repubblica delle Due Nazioni del XVI secolo", From Ireland to Poland, Northern Europe, Spain and the early Modern World, Valencia, Albatros, pp. 79-98.

Conde Pazos, M. (2016), "The Hispanic Monarchy facing the accession of The Vasa Monarchy. Don Guillén de San Clemente's embassy to Poland (1588-1589)", The House of Vasa and The House of Austria. Correspondence from the Years 1587 to 1668, Katowice, WUŚ, pp. 95-114. 
Crăciun, M. (2011), "Traditional Practices: Catholic Missionaries and Protestant Religious Practice in Transylvania", Religion and superstition in Reformation Europe, Manchester University Press, pp. 75-93.

Frost, R. I. (2000), The Northern Wars 1558-1721, Harlow, Longman.

Garnstein, O. (1992), Rome and the Counter-Reformation in Scandinavia: Jesuit Educational Strategy, 1553-1622, Leiden, Brill.

Gómez-Centurión, C. (1988), Felipe II, la empresa de Inglaterra y el comercio septentrional (1566-1609), Madrid, Naval.

González Cuerva, R. (2006), “'El prodigioso príncipe transilvano' la larga guerra contra los turcos (1596-1606) a través de las 'relaciones de sucesos"', Studia historica. Historia moderna, 28, pp. 277-299.

- (2007), "El turco a las puertas: política oriental de Felipe III", en La monarquía de Felipe III: Ios Reinos, Madrid, Mapfre, Vol. IV, pp. 1447-1480.

Herrera y Tordesillas, A. (1612), Historia general del mundo... del tiempo del rey d. Felipe II el Prudente, desde el año de 1585 hasta el de 1598, Madrid, Imprenta Alonso Martín de Balboa.

Hortal Muñoz, J. E. (2004), El manejo de los asuntos de Flandes, 1585-1598, tesis doctoral, UAM.

Jarmiński, L. (2012), "Projekt oddania szwedzkiego portu Älvsborg do dyspozycji Filipa II w świetle akt nuncjatury Germanica Malaspiny", Nuncjatura Apostolska w Rzeczypospolitej, Białystok, IHiNP UWB, pp. 177-183.

Klaniszay, T. (1983), "Gli antagonism tra Corte e società in Europa centrale: la Corte transilvanica alla fine del XVI secolo" Cheiron, 1, pp. 31-58

Kołodziejczyk, D. (2000), Ottoman-Polish Diplomatic Relations (15 ${ }^{\text {th }}-18^{\text {th }}$ Century), An Annotated Ed. Of Ahnames and Other Documents, Leiden, Brill.

Kortepeter, C. M. (1972), Ottoman Imperialism During the Reformation: Europe and the Caucasus, New York Un. Press.

Kruppa, T. (2004), Erdély és a Szentszék a Báthory korszakban. Kiadatlan iratok (15741599). Vatican papers. Relationships between Transylvania and the Holy See under the Báthorys (1574-1599), Szeged.

- (2014), "Apostolic Nunciature in a Protestant Country: the Transylvanian Mission of Alfonso Visconti, Bishop of Cervia (1595-1598)", Il Papato e le Chiese locali, Viterbo, Sette Citta, pp. 89-117.

Lukács, L. (1987), Monumenta Antiquae Hungariae IV (1593-1600), Roma, Institutum Historicum Societatis lesu.

Martínez Millán, J., Carlos Morales J. C. de (1998), Felipe II (1527-1598). La configuración de la Monarquía Hispana. Valladolid, Junta de Castilla y León.

Milewski, D. (2012), "Campaign of the Great Hetman Jan Zamoyski in Moldavia (1595). Part I. Politico-diplomatic and military preliminaries", Codrul Cosminului, XVIII, 2, pp. 261286.

Oakley, S. P., (1992), War and Peace in the Baltic 1560-1790, Londres, Routledge.

Ochoa Brun, M. A. (2000), Historia de la diplomacia española, Madrid, Biblioteca Diplomática Española, Vol. VI.

Pärnanen, J. A. (1912), Sigismond Vasa et la succession au trône de Suède 1592-1594, Génova, Chaulmontet.

Przezdziecki, C. R. (1934), Diplomatie et Protocole à la Cour de Pologne, París, Les Belles Lettres.

- (1947), "Embajadas españolas", Boletín de la Real Academia de la Historia, 121.

Roberts, M. (1986), The Early Vasas, a History of Sweden 1523-1611, Cambridge, Cambridge University Press. 
Rodríguez Villa, A. (1899), "D. Francisco de Mendoza, Almirante de Aragón", Homenaje a Menéndez y Pelayo en el año vigésimo de su profesorado, estudios de erudición española, Madrid, Librería General de Victoriano Suárez, vol. I, pp. 487-610.

Sambrian, O. A. (2013), "Deformar con la palabra: la mistificación de la imagen de Segismundo Báthory en el teatro mediante los relatos de Alfonso Carrillo", Laberinti, 152, pp. 541-554.

Sanz Ayán, C. (2012), "Elementos para la construcción de la imagen ideal de un príncipe cristiano 'de Frontera': Segismundo Bathory, Príncipe de Transilvania”, Hispania Félix, 3, pp. 213-248

Skowron, R. (1997), Dyplomaci polscy w Hiszpanii w XVI i XVII wieku, Cracovia, Universitas.

- (2008): Olivares, los Vasa y el Mar Báltico. Polonia en la política internacional de España en los años 1621-1632, Varsovia, DiG.

Türk, A. (2000), The Crimean Khanate under the Reign of Gazi Giray II, Ankara, Bilkent University.

Türkçelik, E. (2012), Cigalazade Yusuf Sinan Pasha y el Mediterráneo entre 1591-1606, tesis doctoral UAM.

- (2015), "El Imperio Otomano y la política de alianzas: las relaciones franco-otomanas en el tránsito del siglo XVI al XVII", Hispania: Revista española de historia, 75, 249, pp. 39-68

Tygielski, W. (1990), Politics of Patronage in Renaissance Poland: Chancellor Jan Zamoyski, His Supporters and the Political Map of Poland, 1572-1605, Varsovia, W. Warszawskiego.

- (2010), "Jan Zamoyski", en K|S|A|P XX LAT, Varsovia, Krajowa Szkoła, pp. 239-257.

Urjasz-Raczko, M. (2014), "La estrategia diplomática de Felipe II frente a la tercera elección libre en la república polaco-lituana, 1586-1589", Studia Histórica, 36, pp. 213-232.

Valera, J. (2000), Correspondencia, Alicante, Biblioteca Virtual Miguel de Cervantes.

Vynar, L. (1975), Habsburgs and Zaporozhian Cossacks: the diary of Erich Lassota von Steblau, 1594, Kansas, Ukrainian Ac. Press. 